\title{
Bioequivalence of Two Formulations of Salmeterol Xinafoate/Fluticasone Propionate HFA pMDI in Healthy Volunteers
}

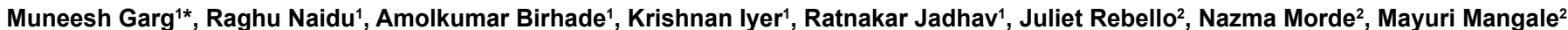
and Bill Brashier ${ }^{2}$

${ }^{1}$ Sitec Labs Pvt. Ltd., PEE-DEE Info Tech, Plot No. Gen-40, TTC MIDC, Near Nelco, Behind Millennium Business Park, Mahape, Navi Mumbai- 400710, India

${ }^{2}$ Cipla Ltd., Cipla House, Peninsula Business Park, Ganpatrao Kadam Marg, Lower Parel, Mumbai 400013 , India

\begin{abstract}
In the treatment of asthma, salmeterol xinafoate and fluticasone propionate are known to be effective and well accepted. These studies determined the bioequivalence between the test and reference formulations of salmeterol xinafoate/fluticasone propionate HFA pMDI, in healthy volunteers. Four pharmacokinetic studies were performed with the two higher strengths $(25 / 250 \mathrm{mcg}$ per actuation) and the two lower strengths (25/125 mcg per actuation) of the test and reference formulation. In all studies, the evaluation was based on a single dose, randomized, crossover design with a minimum washout period of 14 days. Out of the four studies, two studies also evaluated pulmonary deposition by blocking gastrointestinal absorption using charcoal administration for each strength. Examinations for safety included monitoring of adverse events and vital signs along with clinical laboratory assessments. A validated LC-MS/MS technique was used to determine the plasma concentrations of salmeterol xinafoate and fluticasone propionate. For the studies without charcoal blockade for salmeterol, the $90 \% \mathrm{Cl}$ for $\mathrm{C}_{\mathrm{max}}$ and $\mathrm{AUC}$, for $25 / 250 \mathrm{mcg}$ was 83.44-100.29 and 104.08-120.08 respectively, while for $25 / 125 \mathrm{mcg}$ it was $88.33-106.08$ and $100.49-114.88$ respectively. Similarly, in the studies with charcoal blockade for salmeterol, the $90 \% \mathrm{Cl}$ for $\mathrm{C}_{\max }$ and $\mathrm{AUC} \mathrm{C}_{0-1}$ for $25 / 250$ mcg was $94.10-113.20$ and 96.44-116.69 respectively, while for $25 / 125 \mathrm{mcg}$ it was $100.70-115.72$ and $104.99-122.70$ respectively. For fluticasone, the $90 \% \mathrm{Cl}$ for $C_{\text {max }}$ and $A U C_{0-t}$ for $25 / 250 \mathrm{mcg}$ was $91.08-105.07$ and $99.86-115.61$ respectively and for $25 / 125 \mathrm{mcg}$, it was $87.04-105.03$ and $85.38-103.42$ respectively. Since the $90 \% \mathrm{Cl}$ for $\mathrm{C}_{\max }$ and $A \cup C_{0-1}$ for both salmeterol and fluticasone were within the $80-125 \%$ interval in all the studies, it was concluded that test and reference formulations of salmeterol xinafoate/fluticasone propionate HFA pMDI are bioequivalent in their rate and extent of absorption with and without charcoal blockade for both the strengths.
\end{abstract}

Keywords: Salmeterol xinafoate; Fluticasone propionate; pMDI; 25/250 mcg;25/125 mcg; Inhalational; Bioequivalence, Pharmacokinetics

Abbreviations: $\mathrm{AE}$ : Adverse event; $\mathrm{AUC}_{0-\mathrm{t}}:$ Area under the plasma concentration versus time curve from time 0 to time $t$; $\mathrm{AUC}_{0 \text {-inf: }}$ : Area under the plasma concentration versus time curve from time 0 extrapolated to infinity; CFC: Chlorofluorocarbon; $\mathrm{C}_{\max }$ : Maximum plasma concentration; $\mathrm{CI}$ : Confidence interval; $\mathrm{CV}$ : coefficient of variation; ${ }^{\circ} \mathrm{C}$ : Degree centigrade; $\mathrm{cm}$ : Centimeter; EMA: European Medicine Agency; ECGs: Electrocardiograms; gms: Grams; $\geq$ : Greater than or equal to; GCP: Good clinical practice; GINA: Global Initiative for Asthma; GI: Gastro-intestinal; HFA: Hydrofluoroalkane; hr(s): Hour(s); ICS: Inhaled corticosteroids; K: Elimination rate constant; $\mathrm{kg}(\mathrm{s})$ : Kilogram(s); LC-MS/MS: Liquid Chromatography-Mass Spectroscopy/ Mass Spectroscopy; $\leq$ : less than or equal to; LABA: Longacting $\beta_{2}$-agonist; LOQ: Lower limit of quantification; L/min: Liters/ minute; $\operatorname{Min}(\mathrm{s})$ : Minute(s); mm: Millimeter; m: Meter; mL: Milli liter; mM: millimol; $\mu$ : Microliter; $\mu \mathrm{g}$ : Micro gram; ng/mL: Nano gram/ Milliliter; OIPs: Orally inhaled products; pMDI: pressurized metered dose inhaler; \%: Percent; PD: pharmacodynamics; PK: Pharmacokinetic; rpm: Rotations per minute; SAE: Serious adverse event; SAS: Statistical analysis software; $\mathrm{T}_{\max }$ : Time to reach $\mathrm{C}_{\max } ; \mathrm{t}_{1 / 2}$ : Elimination half-life; UK: United Kingdom; yr.(s): Year(s).

\section{Introduction}

Asthma is an inflammatory airway disease and it causes serious health complications to patients and a massive economic burden on societies [1].

For patients with persistent asthma, inhaled corticosteroids (ICS) have been the first-line treatment regardless of disease severity. Considering the guidelines, patients with asthma who are not sufficiently well controlled with ICS alone (plus a fast-acting bronchodilator used whenever required) should have added a long-acting $\beta_{2}$-agonist (LABA). As reported in the GINA guidelines, the administration of a combination inhaler containing both ICS and LABA in patients with asthma ensures that the LABA is not administered alone $[1,2]$.

Seretide Evohaler (UK) (Salmeterol/fluticasone propionate metered dose pressurised inhalation suspension-reference combination inhaler) is a fixed-dose combination containing a LABA+ICS. Salmeterol is a selective LABA, which causes bronchodilation and inhibition of the release of hypersensitivity mediators from mast cells. The corticosteroid fluticasone propionate inhibits eosinophil activation and the subsequent release of inflammatory mediators [2].

This combination therapy serves as an evident scientific rationale as LABA and ICS may optimize each other's favorable actions in the airways [3].

Cipla Ltd has developed a salmeterol/fluticasone combination delivered by a metered dose inhaler (test combination inhaler).

*Corresponding author: Muneesh Garg, MD Pharmacology, Principal Investigator Sitec Labs Pvt. Ltd., PEE-DEE Info Tech, Plot No. Gen-40, TTC MIDC, Near Nelco, Behind Millennium Business Park, Mahape, Navi Mumbai- 400710, India, Tel: +91 9833913773; Fax: +91 222778 6241; E-mail: muneesh.garg@siteclabs.com

Received August 25, 2017; Accepted October 04, 2017; Published October 16 2017

Citation: Garg M, Naidu R, Birhade A, lyer K, Jadhav R, et al. (2017) Bioequivalence of Two Formulations of Salmeterol Xinafoate/Fluticasone Propionate HFA pMDI in Healthy Volunteers. J Bioequiv Availab 9: 536-546. doi: 10.4172/jbb.1000359

Copyright: @ 2017 Garg M, et al. This is an open-access article distributed under the terms of the Creative Commons Attribution License, which permits unrestricted use, distribution, and reproduction in any medium, provided the original author and source are credited. 
The product has been developed by following the European Medicine Agency (EMA) guideline on the requirements for clinical documentation for orally inhaled products (OIPs) [4]. According to the guideline, a second entry orally inhaled combination product has to demonstrate therapeutic equivalence with the reference combination product for both active substances of the test combination product. In case therapeutic equivalence cannot be proven based on in vitro data, pharmacokinetic $(\mathrm{PK})$ and/or clinical studies are required. We report here the results of four PK studies that evaluated equivalence in pulmonary deposition (lung dose after blocking of the gastro-intestinal (GI) uptake with charcoal) and systemic exposure (without charcoal blockade) after inhalation of a single dose of two formulations of salmeterol/fluticasone.

\section{Materials and Methods}

\section{Study drugs}

Seretide Evohaler $(25 \mathrm{mcg}$ salmeterol/125 mcg fluticasone per inhalation and $25 \mathrm{mcg}$ salmeterol/250 mcg fluticasone per inhalation) were the reference products (hereafter referred to as Seretide Evohaler 25/125 and Seretide Evohaler 25/250). For charcoal block charcoal powder (Carbomix $50 \mathrm{gm}$, Beacon Pharmaceuticals, UK) was utilized [5].

In all the studies, a single dose of the test formulation of salmeterol xinafoate/fluticasone propionate HFA pMDI 50/500 (25/250 mcg per actuation $\times 2$ puffs) or salmeterol xinafoate/fluticasone propionate HFA pMDI 50/250 (25/125 mcg per actuation $\times 2$ puffs $)$ manufactured by CIPLA LIMITED, INDIA was compared with similar doses of the reference formulation of Seretide ${ }^{\mathrm{TM}}$ Evohaler $^{\mathrm{TM}}$ supplied by ALLEN AND HANBURYS LTD., UK. The doses assessed with each strength were the recommended doses as mentioned in the summary of product characteristics.

\section{Volunteers}

For these studies, healthy male volunteers aged $18-45$ years with a body mass index $\geq 18.5 \mathrm{~kg} / \mathrm{m}^{2}$ and $\leq 25.00 \mathrm{~kg} / \mathrm{m}^{2}$, a forced expiratory volume in one second $\left(\mathrm{FEV}_{1}\right) \geq 80 \%$ of predicted normal, and good general health were selected. The volunteers were declared to be healthy based on prior medical history, physical examination, ECG, chest X-ray, pulmonary function test (spirometry), pulse oximetry, and clinical laboratory test results.

Volunteers were excluded from the PK studies if they had known history of hypersensitivity to salmeterol xinafoate or fluticasone propionate or any component of the product, or related class of drug; had history of chronic bronchitis, emphysema, asthma or any other lung disease of clinical significance; had recent upper or lower respiratory tract infection; had consumed drugs that induce/inhibit the hepatic microsomal enzymes two months prior to dosing; and had ingested any herbal product, prescribed or non-prescribed drug four weeks prior to dosing and throughout the study.

\section{Informed and ethical consent}

The Independent Ethics Committee (IEC) reviewed the protocol and informed consent forms (ICFs) and approved them before the initiation of the studies. The IEC was Dakshata, an Independent Ethics Committee which approved all the studies. Volunteers were informed in the language they understand about the purpose, nature, procedure, duration, anticipated risks and discomfort of the study. They were given sufficient time to read and understand the ICF and a written informed consent was obtained from each one of them prior to study participation. All studies were conducted at Sitec Labs, Mumbai India as per the Declaration of Helsinki, Good Clinical Practice guidelines and national regulatory guidelines [6-9].

\section{Study design}

This report summarizes the four PK studies comparing the two strengths of the test combination inhaler with similar strengths of the reference combination inhaler. For each strength, lung deposition of salmeterol was assessed by blocking gut absorption using charcoal blockade. The charcoal regimen used to block the GI absorption of salmeterol was as follows: immediately before study drug administration ( 2 minutes prior to the first puff), the mouth was thoroughly rinsed with $50 \mathrm{~mL}$ (approximately $5 \mathrm{gm}$ ) of charcoal suspension before swallowing. This was repeated at 2 minutes after the first puff, followed by $100 \mathrm{~mL}$ (approximately $10 \mathrm{gm}$ ) of charcoal suspension at 1.00, 2.00 and 3.00 hours post-dose. The method of charcoal administration has been validated in a study conducted by Bennett et al. [10]

Fluticasone propionate has negligible oral bioavailability $(<1 \%)$ due to a combination of incomplete absorption from the gastro-intestinal tract and extensive first-pass metabolism, therefore systemic exposure arises only from pulmonary absorption i.e. lungs [11-13]. The amount of drug that reaches the blood via absorption from the lungs is same as the total bioavailability of the drug. Therefore, use of oral charcoal blockade to block the gastrointestinal absorption of inhaled fluticasone propionate for comparison of the pulmonary bioavailability of the test product and the reference product was not required.

The systemic exposure of the active moieties was assessed in the PK studies without charcoal blockade. All studies were single dose, randomized, crossover studies. The studies consisted of a screening period, two or four treatment days separated by at least 14-day washout periods, and an end-of-study visit occurring at least 14 days after the last study treatment administration.

Studies with 25/250 mcg strength: The pivotal Study-1 (four-way, replicate design) evaluated lung deposition of salmeterol after a single dose $50 / 500 \mathrm{mcg}$ (administered as 2 puffs of $25 / 250 \mathrm{mcg} / \mathrm{puff}$ ) in 42 healthy volunteers. This study utilized a replicate design with a large sample size to take into account the potential for a high coefficient of variation that can be observed for the PK parameters for SM in charcoal blockade studies. Further, since the use of charcoal is unlikely to have a significant effect on the magnitude of bioavailability of fluticasone due to its negligible oral bioavailability, fluticasone was not evaluated in this study.

In the pivotal study-2 (two-way design), 74 healthy male volunteers were studied after a single dose of $50 / 500 \mathrm{mcg}$ (administered as 2 puffs of $25 / 250 \mathrm{mcg} /$ puff) on each of the treatment days (without charcoal blockade). This study evaluated the systemic exposure of both salmeterol and fluticasone and also the lung deposition of fluticasone.

Studies with 25/125 mcg strength: The pivotal Study-3 was a randomized, single dose, four-way crossover pharmacokinetic study in 80 volunteers to compare the test product with the reference product with and without charcoal administration. A single dose of 50/250 mcg (administered as 2 puffs of $25 / 125 \mathrm{mcg} /$ puff) was administered. As the oral bioavailability of fluticasone propionate is very low $(<1 \%)$, fluticasone propionate was only evaluated in the treatment arms without charcoal administration while salmeterol was evaluated both with and without charcoal administration.

The pivotal Study-4 (four-way, replicate design) evaluated lung 
deposition of salmeterol after a single dose 50/250 mcg (administered as 2 puffs of $25 / 125 \mathrm{mcg} /$ puff) using charcoal blockade in 72 healthy volunteers. This study was conducted as the earlier pivotal study- 3 showed high variability in the treatment arms using charcoal blockade.

In all studies the volunteers were trained in the correct use of the inhalers at the screening visit and before each study drug administration. They were trained on the inhalation technique with the help of an incheck dial, aerosol inhalation monitors and a placebo (inactive) inhaler. The volunteers were carefully instructed by the trainer on the inhalation technique as described in the manufacturer's leaflet.

\section{Study drug administration}

The test and the reference products were primed within 10 minutes prior to dosing by releasing 2 test sprays, away from the volunteer's blood sample tubes or supplies. After priming, the test or the reference product was inhaled; there was a gap of at least 30 seconds between each puff inhaled by the volunteer. The treatments were self-administered by the volunteers after an overnight fast of at least 10 hours in each period under the supervision of the trained and qualified pharmacist, quality assurance personnel, quality control personnel and the sponsor's monitor. Study volunteers were confined to the study facility from at least $12 \mathrm{hr}$ prior to dosing until at least $24 \mathrm{hr}$ after dosing. During housing, post-dose meals were identical for all the periods of the study. Lunch, snacks and dinner were served at 4.0, 9.0 and 13.0 hours, respectively, after dosing. Water was not permitted from 1 hour before dosing until 1 hour following dosing, but it was allowed thereafter.

The test and reference formulations of salmeterol xinafoate/ fluticasone propionate HFA pMDI were stored in a pharmacy under controlled conditions of temperature $\left(22 \pm 3^{\circ} \mathrm{C}\right)$ and at 50 to $60 \%$ relative humidity and the conditions were monitored continuously.

\section{Blood sampling}

The samples of blood for salmeterol xinafoate/salmeterol xinafoate and fluticasone propionate test, were collected via an indwelling catheter (intra-venous) with respect to start time of first puff in vacutainers containing (dipotassium ethylene diamine tetraacetic acid) $\mathrm{K}_{2}$ EDTA anticoagulant.

The content and the blood sample in the vacuum collection tubes are mixed well by inverting them gently, after the collection of the blood. Tubes containing blood samples were immediately placed in an iced water bath at approximate temperature below $12^{\circ} \mathrm{C}$ till they were centrifuged. The blood sample tubes were centrifuged to separate plasma as soon as possible at $3000 \mathrm{rpm}$ for 10 minutes in a centrifuge set at a temperature of $8^{\circ} \mathrm{C}$. The plasma samples were divided in two portions (main and reserve). Then plasma samples were stored at $-70^{\circ} \mathrm{C}$ or below until sample analysis.

Blood samples for the determination of fluticasone and salmeterol concentrations in plasma were drawn before the administration of the study treatments and up to $36 \mathrm{~h}$ after drug administration (except in pivotal study- 1 where the sampling was up to $18 \mathrm{~h}$ post dose).

The sampling time points (hours: minutes) were at $-1.00 \mathrm{~h}$ (predose) and after the administration of the study drugs at: $0.05,0.08$, $0.17,0.25,0.50,0.75,1.00,1.25,1.50,1.75,2.00,2.50,3.00,4.00,6.00$, $8.00,10.00,12.00,14.00,16.00,18.00,24.00$ and $36: 00 \mathrm{hr}$ post dose. In pivotal study- 1 the sampling time points post dose excluded 0.75 , $1.25,1.50,1.75,2.50,3.00$ and $24 \mathrm{~h}$. Since, this was the first study to be conducted with charcoal blockade assessing only salmeterol, hence the intermediate time points relevant to fluticasone $(0.75,12.5,1.50$,
$1.75,2.50$ and $3 \mathrm{~h}$ ) were not included. Further, since lower plasma concentrations were expected due to charcoal blockade, sampling for salmeterol was done only till 18 hours.

Fluticasone and salmeterol concentrations in plasma were determined by separate, validated liquid chromatography-tandem mass spectrometry (LC-MS/MS) methods at Sitec Labs, Mumbai, India.

The volunteers were required to refrain from consuming any food and beverages containing xanthine or alcohol ( $48 \mathrm{~h}$ before dosing and for $24 \mathrm{~h}$ after each dose), grapefruit (7 days before dosing and throughout the study), or vitamins (throughout the confinement period). On check in day, at least $12 \mathrm{hr}$ prior to each dosing, all volunteers were screened for drugs of abuse (cocaine, cannabinoids, benzodiazepines, Opioids, Amphetamines, and barbiturates) by urine test, and for alcohol consumption by breath alcohol test.

\section{Pharmacokinetic analysis}

As primary markers of efficacy and safety, the following variables were calculated from concentration-time curves for fluticasone and salmeterol after study drug administration: the maximum observed concentration of concentration-time curve $\left(\mathrm{C}_{\max }\right)$ and the area under the concentration-time curve from time zero to the last sample with quantifiable drug concentration $\left(\mathrm{AUC}_{\mathrm{t}}\right)$ calculated with the linear trapezoidal rule. The secondary $\mathrm{PK}$ parameters were the area under the concentration-time curve from time zero to infinity ( AUC $_{\infty}$ ) determined by adding $\mathrm{AUC}_{t}$ to the extrapolated area that was determined dividing the last quantifiable concentration by $\mathrm{K}_{e}\left(\mathrm{~K}_{e}=\right.$ the terminal elimination rate constant from log-linear portion of a concentration-time curve), the time to reach the maximum concentration $\left(\mathrm{t}_{\max }\right)$, and the terminal elimination half-life $\left(\mathrm{t}_{1 / 2}\right)$ calculated with the equation $\ln _{2} / \mathrm{K}_{\mathrm{e}}$. The same $\mathrm{PK}$ variables as above were calculated in all the 4 studies. The PK parameters were calculated by a non-compartmental method using the WinNonlin version 3.6 computer program. The actual time of sampling was used in the calculations. The zero time was the start of the first inhalation of the active study treatment.

Clinical safety was assessed by monitoring adverse events, physical examination and vital signs as well as performing clinical laboratory tests.

\section{Statistical analysis}

The determination of sample size for individual studies was based on previous studies with the developmental formulations of fluticasone/salmeterol product. The reported variability of salmeterol was the highest for the primary parameters and was therefore used in the sample size calculations. It was assumed that the expected ratio of means would be $0.95-1.1$ in order to demonstrate that the $90 \%$ CI for bioequivalence in a crossover study design will be within $80-125 \%$ with $90 \%$ power at a $5 \%$ level of significance. Per protocol (PP) data set was used when comparing the PK results.

The PP data set excluded all the subjects who discontinued, had a major protocol deviation, or insufficient number of PK samples for the calculation of reliable PK parameters.

The primary $\mathrm{PK}$ variables $\mathrm{C}_{\max }$ and $\mathrm{AUC}_{\mathrm{t}}$, were analyzed using analysis of variance (ANOVA). The responses were modeled using logarithmic transformations. By taking exponential backtransformations, the results were returned to the original scale, yielding the ratio of geometric means and their $90 \%$ confidence intervals (CIs). These CIs were evaluated against the conventional $\mathrm{BE}$ region from 0.80 to 1.25 . The secondary $\mathrm{PK}$ variables were $\mathrm{AUC}_{\infty}, \mathrm{AUC}_{\infty}$ was analyzed 
in the same way as $\mathrm{C}_{\max }$ and $\mathrm{AUC}_{\mathrm{t}}$. Wilcoxon Signed Rank Sum Test for paired samples was used for analysis of $\mathrm{T}_{\max }$. All statistical analyses were performed with SAS for Windows release 9.3 (SAS Institute Inc., Cary, NC, USA).

\section{Randomization and Blinding techniques}

The volunteers were randomized to the test and reference group by using SAS software. All four studies were open-label, where the investigators knew the type of the formulations administered in each study period. However, the randomization list was not available to the bio-analytical team at Sitec Labs until the analysis was completed.

\section{Analytical methods}

The concentrations of Fluticasone and Salmeterol in the plasma samples of the subjects were determined using separate validated LCMS/MS based bio-analytical methods in accordance with the principles of Good Laboratory Practice (GLP). The bio-analytical methods were developed and validated at Sitec Labs (P) Ltd. as per the international guidelines [14,15]. Fluticasone and Salmeterol were extracted from human plasma using Solid Phase Extraction (SPE) procedure and injected into the liquid chromatograph coupled with tandem MS/ MS detector. To avoid bias, the analyst did not have access to the randomization code. Samples for any given subject for all time points were assayed under similar chromatographic conditions that were validated for the analysis of salmeterol/fluticasone in human plasma. For both the analytical methods, the validation parameters were system suitability, carry over test, specificity and selectivity, matrix effect (postextraction addition and post-column infusion), sensitivity, linearity (calibration curve), precision and accuracy, ruggedness, haemolysis effect, recovery, stability under different conditions, plasma dilution integrity and re-injection reproducibility.

All the analytical methods were validated according to the latest regulatory guidelines (CDER 2013 and EMA 2012).

Fluticasone assay: Fluticasone propionate was extracted from plasma samples $(500 \mu \mathrm{l})$ using SPE method involving C18 cartridges. Plasma samples were spiked with internal standard and subsequently $500 \mu \mathrm{l}$ of $30 \%$ methanol was added to each sample. These samples were loaded on cartridges and washed with a mixture of acetonitrile and water followed by elution with acetonitrile. The eluted solvent was then mixed with $2 \mathrm{mM}$ Ammonium trifluroacetate buffer and samples were analysed on LC-MS/MS. The LC-MS/MS comprised of Shimadzu UFLC (LC) and Sciex 5500 (MS/MS) triple quadrapole mass spectrometer. A monolithic RP18 column was used with a mobile phase comprising of acetonitrile and buffer. The flow rate of mobile phase was $1.0 \mathrm{~mL} / \mathrm{min}$ and the chromatographic run time was $2.0 \mathrm{~min}$. The mass spectrometer was operated in positive ionization mode and Fluticasone and internal standard (Fluticasone D3) were monitored using MRM transition 501.20/293.20 and 504.20/313.20 respectively. The lower limit of quantitation was $2.0 \mathrm{pg} / \mathrm{mL}$ and calibration standards ranged from 2.0 to $250 \mathrm{pg} / \mathrm{mL}$.

Four precision and accuracy sets (P \& A set) were analysed during method validation and each $\mathrm{P} \& \mathrm{~A}$ set consisted of seven $\mathrm{QCs}$ each at five different concentration levels (LLOQ QC, Low QC, Mid QC A, Mid QC-B \& High QC). The within batch precision (\%CV) ranged from 1.38 to $19.18 \%$ and the within batch accuracy (\%Nominal) ranged from $90.00 \%$ to $110.00 \%$. The between batch precision (\%CV) ranged from $2.39 \%$ to $14.55 \%$ and the between batch accuracy (\%Nominal) ranged from $96.72 \%$ to $105.00 \%$. The between batch precision and accuracy during the study are presented in Table 1.

For $25 / 250 \mathrm{mcg}$, the performance of analytical method was monitored during the study using quality control samples at concentrations $6.0,30,100$ and $200 \mathrm{pg} / \mathrm{mL}$.

For the 25/125 mcg, the first ten subjects were analysed with calibration range of 2.0 to $250 \mathrm{pg} / \mathrm{mL}$ and based on the concentration data obtained the calibration range was modified to 2.0 to $100 \mathrm{pg} /$ $\mathrm{mL}$ for the remaining part of the study. The performance of analytical method was monitored during the study using quality control samples at concentrations $6.0,30,100$ and $200 \mathrm{pg} / \mathrm{mL}$ for calibration ranged 2.0 to $250 \mathrm{pg} / \mathrm{mL}$ and $6.0,20,55$ and $85 \mathrm{pg} / \mathrm{mL}$ for the calibration range of 2.0 to $100 \mathrm{pg} / \mathrm{mL}$. The performance of the Fluticasone assay method during pivotal studies is summarized in Table 1.

During study sample analysis, quality control samples were distributed throughout each batch. Samples for any given subject for all time points were assayed under similar chromatographic conditions that were validated for the analysis of Fluticasone in human plasma.

Salmeterol assay: Salmeterol was extracted from plasma samples using SPE method involving mixed mode anion exchange cartridges. Plasma samples were spiked with internal standard and subsequently $500 \mu \mathrm{l}$ of $100 \mathrm{mM}$ Ammonium acetate was added to each sample. These samples were loaded on cartridges and washed with a mixture of methanol and water followed by elution with $20 \%$ acetonitrile. The eluted samples were analysed on LC-MS/MS. The LC-MS/MS comprised of Shimadzu UFLC (LC) and Sciex 5500 (MS/MS) triple quadrapole mass spectrometer.

The analytical column used in the bioanalytical method for the $25 / 250 \mathrm{mcg}$ study (Study-1) was ACE 3 C18 (100 mm, $3 \mathrm{~mm}$ ) column. The mobile phase comprised of mixture of Acetonitrile, $5 \mathrm{mM}$ ammonium trifluroacetate buffer and isopropyl alcohol. The flow rate of mobile phase was $0.5 \mathrm{~mL} / \mathrm{min}$ and the chromatographic run time was $3.2 \mathrm{~min}$. The mass spectrometer was operated in positive ionization mode and Salmeterol and internal standard (Salmeterol D3) were monitored using MRM transition 416.30/232.10 and 419.30/235.20 respectively.

The lower limit of quantitation was $2.0 \mathrm{pg} / \mathrm{mL}$ and calibration standards ranged from 2.0 to $2000 \mathrm{pg} / \mathrm{mL}$. Four precision and accuracy

\begin{tabular}{|c|c|c|c|c|}
\hline & Between batch precision (\% CV) & Between batch accuracy (\%Nominal) & Calibration standard range & $\begin{array}{l}\text { Incurred sample } \\
\text { reanalysis: (\%) }\end{array}$ \\
\hline \multicolumn{5}{|c|}{ 25/250 mcg (Dose 50/500 mcg) } \\
\hline During Pivotal study 2 & 3.10 to 8.05 & 99.67 to 100.79 & 2.0 to $250 \mathrm{pg} / \mathrm{mL}$ & 91.96 \\
\hline \multicolumn{5}{|c|}{ 25/125 mcg (Dose 50/250 mcg) } \\
\hline During study- 3 & 3.84 to 6.55 & 93.08 to 94.06 & 2.0 to $250 \mathrm{pg} / \mathrm{mL}$ (for first 10 subjects) & \multirow{2}{*}{84.58} \\
\hline During study- 3 & 5.47 to 8.20 & 98.36 to 101.86 & $2.0-100 \mathrm{pg} / \mathrm{mL}$ (subject number $11-80)^{*}$ & \\
\hline
\end{tabular}

Table 1: Precision and Accuracy of batches during the analytical run of Fluticasone. 
sets (P \& A set) were analysed during method validation and each P \& A set consisted of seven QCs each at five different concentration levels (LLOQ QC, Low QC, Mid QC - A, Mid QC-B \& High QC). The within batch precision $(\% \mathrm{CV})$ ranged from 0.85 to $7.87 \%$ and the within batch accuracy (\%Nominal) ranged from $96.44 \%$ to $105.00 \%$. The between batch precision (\%CV) ranged from $1.86 \%$ to $6.12 \%$ and the between batch accuracy (\%Nominal) ranged from $98.31 \%$ to $100.00 \%$. The between batch precision and accuracy during the study are presented in Table 2 .

The performance of analytical method was monitored during the with charcoal study was monitored using quality control samples at concentrations $6.0,60,500$ and $1500 \mathrm{pg} / \mathrm{mL}$ for calibration ranged 2.0 to $2000 \mathrm{pg} / \mathrm{mL}$ and $6.0,50,100$ and $400 \mathrm{pg} / \mathrm{mL}$ for the calibration range 2.0 to $500 \mathrm{pg} / \mathrm{mL}$.

The analytical method was subsequently modified to improve the chromatography and reduce the run time. The analytical column used in the bioanalytical method for the $25 / 250 \mathrm{mcg}$ study (without charcoal pre-treatment- Study-2) was Chromolith RP18 (100 mm, $3 \mathrm{~mm})$ column. The mobile phase comprised of mixture of Acetonitrile, $5 \mathrm{mM}$ ammonium trifluroacetate buffer and isopropyl alcohol. The flow rate of mobile phase was $0.8 \mathrm{~mL} / \mathrm{min}$ and the chromatographic run time was $2.0 \mathrm{~min}$. The mass spectrometer was operated in positive ionization mode and Salmeterol and internal standard (Salmeterol D3) were monitored using MRM transition 416.30/232.10 and 419.30/235.20 respectively. The performance of analytical method was monitored during the study using quality control samples at concentrations 6.0, 50,100 and $400 \mathrm{pg} / \mathrm{mL}$. During study sample analysis, quality control samples were distributed throughout each batch.

In the study-3, the performance of analytical method was monitored during the study using quality control samples at concentrations 6.0, 50,100 and $400 \mathrm{pg} / \mathrm{mL}$. The analytical method was modified to change the concentration of quality control samples in order to validate the unknown concentration in better manner for the charcoal pre-treatment study. There was no change in the extraction, chromatographic and mass spectrometric method.

In the study-4, the performance of analytical method was monitored during the study using quality control samples at concentrations 6.0,25, 50 and $400 \mathrm{pg} / \mathrm{mL}$. The performance of the Salmeterol assay method during the studies is summarized in Table 2.

\section{Results}

\section{Volunteer disposition and baseline demographic characteristics}

In study-1, a total of 42 volunteers were recruited, but only 39 volunteers completed the study. 3 volunteers were drop-outs in period-4 for personal reasons. Data of remaining 39 volunteers was considered for pharmacokinetic and statistical analysis.

In study-2, a total of 74 volunteers were recruited, but only 66 volunteers completed the study. 8 volunteers were drop-outs in period-2 for personal reasons. Leakage of drug was observed during dosing for 10 volunteers. One volunteer was excluded from fluticasone analysis due to pre-dose concentration $>5 \%$ of $\mathrm{C}_{\max }$ value reported for period-1. Therefore, data of remaining 56 volunteers was considered for salmeterol xinafoate; and 55 volunteers was considered for fluticasone propionate for pharmacokinetic and statistical analysis except for volunteers who were dropped out or discontinued from the study before dosing of period- 2 .

In study-3, a total of 80 volunteers were recruited, but only 72 volunteers completed the study. 7 volunteers were drop-outs for personal reasons. 1 volunteer was discontinued due to AE. Leakage of drug was observed during dosing for 9 volunteers. Data of remaining 63 volunteers was considered for pharmacokinetic and statistical analysis of salmeterol xinafoate and fluticasone propionate without charcoal.

In study-4, a total of 72 volunteers were recruited, but only 69 volunteers completed the study. 2 volunteers were drop-outs for personal reasons. 1 volunteer was discontinued due to AE. Leakage of drug was observed during dosing for 1 volunteer. 1 volunteer was dropped from the statistical analysis due to poorly characterized concentration profile (having less than four $(<4)$ consecutive nonzero concentration data points over the entire sampling duration for all periods). Data of remaining 68 volunteers was considered for pharmacokinetic and statistical analysis of salmeterol xinafoate with charcoal. The demographic data of all recruited volunteers for all the 4 studies are presented in Table 3 .

The blood samples were collected up to $18 \mathrm{hrs}$ post dose for study-1. Mean plasma concentration profile of salmeterol xinafoate with charcoal over the 18-hour pharmacokinetic study is presented in Figure 1 (with charcoal FPSM 25/250 mcg study-1). The blood samples were collected up to $36 \mathrm{hrs}$ post dose for study-2. Mean plasma concentration profile of salmeterol xinafoate without charcoal is presented in Figure 2 and for fluticasone propionate without charcoal is presented in Figure 3 over the 36-hour pharmacokinetic study (without charcoal FPSM 25/250 mcg study-2). The blood samples were collected up to $36 \mathrm{hrs}$ post dose for study-3. Mean plasma concentration profile of salmeterol xinafoate without charcoal is presented in Figure 4 and fluticasone propionate without charcoal are presented in Figure 5 over the 36-hour pharmacokinetic study (with and without charcoal FPSM 25/125 mcg study-3). The blood samples were collected up to $36 \mathrm{hrs}$ post dose for study-4. Mean plasma concentration profile of salmeterol

\begin{tabular}{|c|c|c|c|c|}
\hline & Between batch precision (\% CV) & $\begin{array}{l}\text { Between batch accuracy } \\
\text { (\%Nominal) }\end{array}$ & Calibration standard range & $\begin{array}{c}\text { Incurred sample } \\
\text { reanalysis: (\%) }\end{array}$ \\
\hline \multicolumn{5}{|c|}{$25 / 250 \mathrm{mcg}$ (Dose $50 / 500 \mathrm{mcg}$ ) } \\
\hline During study- 1 (with charcoal) & 1.43 to $4.08 \%$ & 96.72 to $100.09 \%$ & $\begin{array}{c}2.0-2000 \mathrm{pg} / \mathrm{mL} \text { (for } 1 \text { st } 9 \text { subjects } \\
\text { analysed) }\end{array}$ & \multirow[t]{2}{*}{$93.75 \%$} \\
\hline During study- 1 (with charcoal) & 1.79 to $6.29 \%$ & 99.60 to $100.89 \%$ & $2.0-500 \mathrm{pg} / \mathrm{mL}$ (remaining 33 subjects) & \\
\hline \multirow[t]{2}{*}{ During study- 2 (without charcoal) } & 2.61 to $10.45 \%$ & 96.72 to $101.36 \%$ & $2.0-500 \mathrm{pg} / \mathrm{mL}$ & $87.14 \%$ \\
\hline & Between batch precision (\% CV) & $\begin{array}{l}\text { Between batch accuracy } \\
(\% \text { Nominal })\end{array}$ & Calibration standard range & $\begin{array}{l}\text { Incurred sample } \\
\text { reanalysis: (\%) }\end{array}$ \\
\hline \multicolumn{5}{|c|}{ 25/125 mcg (Dose 50/250 mcg) } \\
\hline During study- 3 without charcoal & 3.37 to $8.13 \%$ & 95.08 to $100.82 \%$ & 2.0 to $500 \mathrm{pg} / \mathrm{mL}$. & $87.50 \%$ \\
\hline During study- 4 with charcoal & 2.30 to $8.97 \%$ & 95.96 to $99.52 \%$ & 2.0 to $500 \mathrm{pg} / \mathrm{mL}$. & $95.36 \%$ \\
\hline
\end{tabular}

Table 2: Precision and Accuracy of batches during study of Salmeterol. 
Citation: Garg M, Naidu R, Birhade A, lyer K, Jadhav R, et al. (2017) Bioequivalence of Two Formulations of Salmeterol Xinafoate/Fluticasone Propionate HFA pMDI in Healthy Volunteers. J Bioequiv Availab 9: 536-546. doi: 10.4172/jbb.1000359

\begin{tabular}{|c|c|c|c|}
\hline & Study-1 & Study-2 & Study-3 \\
\hline Number of volunteers & 42 & 74 & 80 \\
\hline Mean Age \pm SD $(\mathrm{yrs})$ & $28 \pm 6$ & $28 \pm 6$ & $27 \pm 6$ \\
\hline Mean Weight \pm SD $(\mathrm{kg})$ & $64.0 \pm 7.6$ & $61.8 \pm 6.2$ & $64.9 \pm 6.9$ \\
\hline Mean Height \pm SD $(\mathrm{m})$ & $1.69 \pm 0.06$ & $1.67 \pm 0.05$ & $1.69 \pm 0.06$ \\
\hline Mean BMI \pm SD $\left(\mathrm{Kg} / \mathrm{m}^{2}\right)$ & $22.3 \pm 2.3$ & $22.1 \pm 2.1$ & $22.7 \pm 1.9$ \\
\hline
\end{tabular}

Table 3: Demographic data.

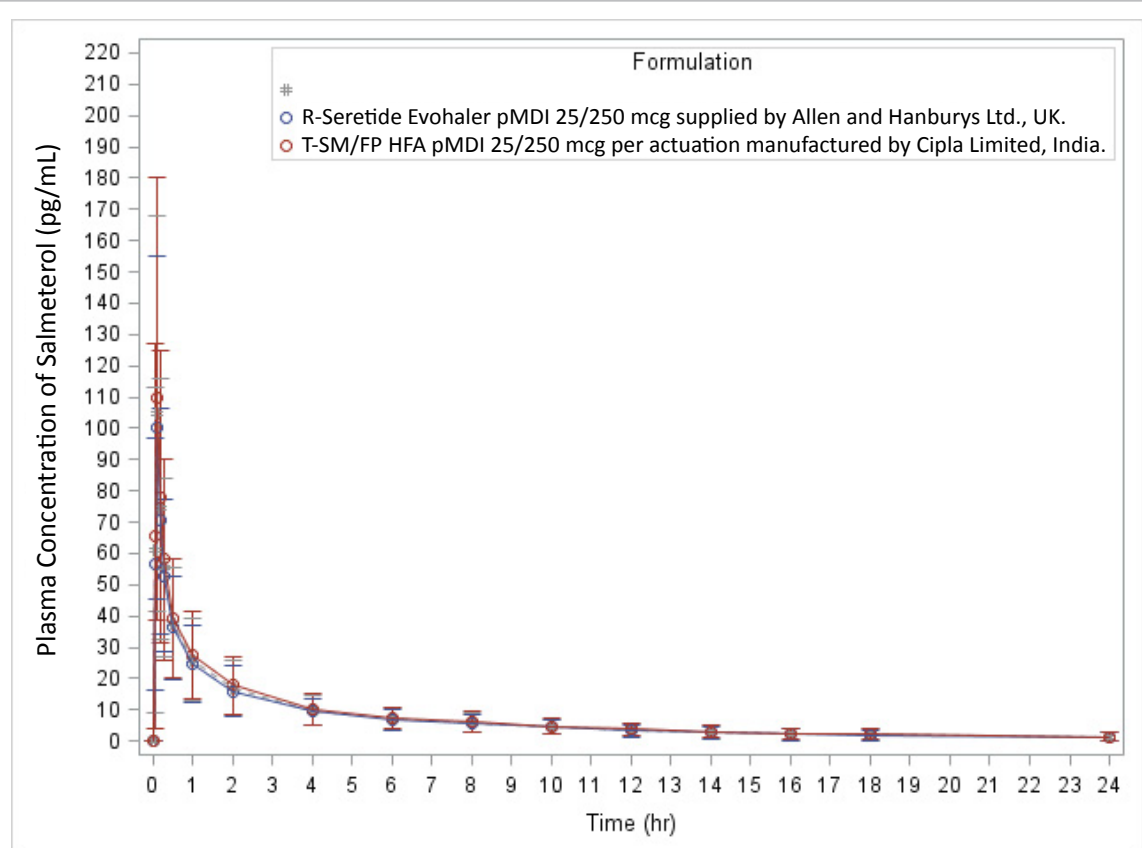

Figure 1: Mean graph (linear) for plasma concentration vs. time profile of Salmeterol xinafoate after inhalational dose of Salmeterol xinafoate/Fluticasone propionate (SM/FP) HFA pMDI 50/500 mcg in Study-1 (Salmeterol xinafoate/Fluticasone propionate (SM/FP) HFA pMDI 25/250 mcg per actuation with charcoal).

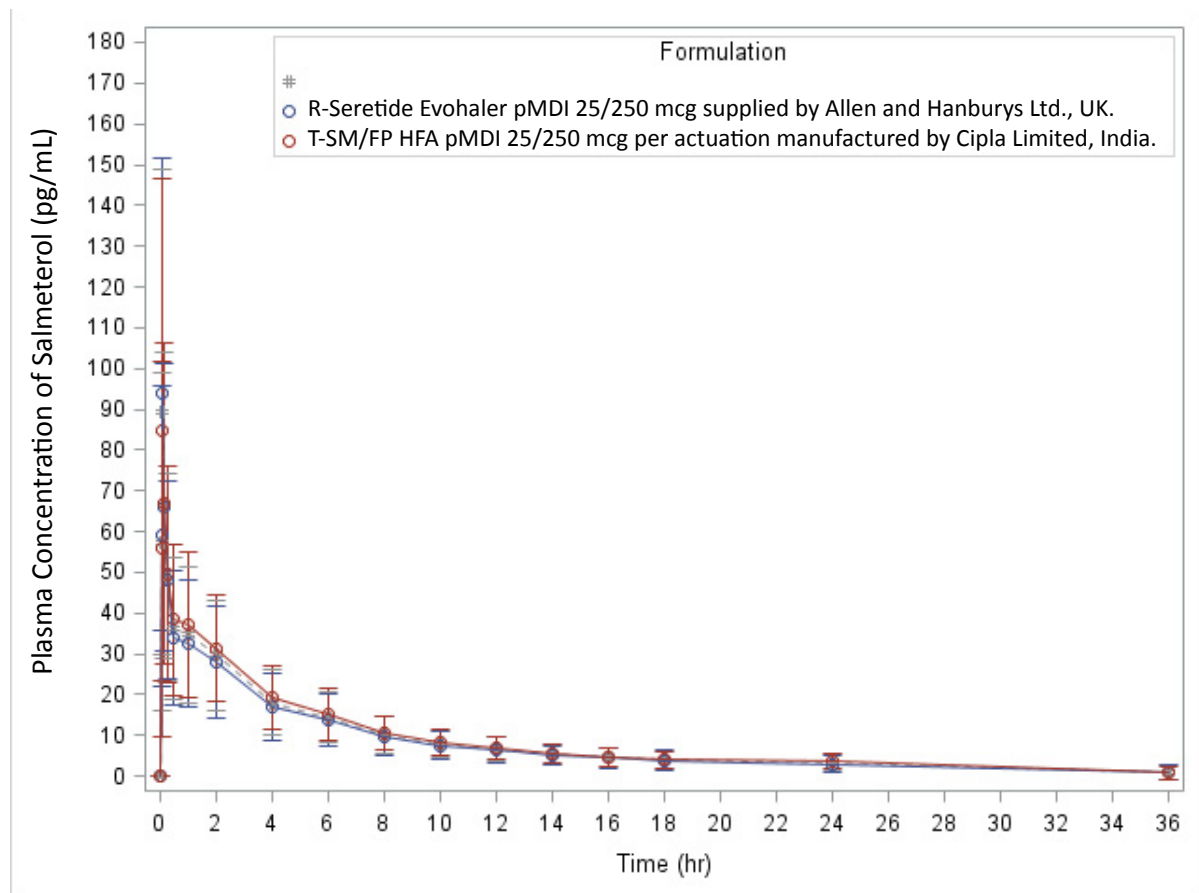

Figure 2: Mean graph (linear) for plasma concentration vs. time profile of Salmeterol xinafoate after inhalational dose of Salmeterol xinafoate/Fluticasone propionate (SM/FP) HFA pMDI 50/500 mcg in Study-2 (Salmeterol xinafoate/Fluticasone propionate (SM/FP) HFA pMDI 25/250 mcg per actuation without charcoal). 
Citation: Garg M, Naidu R, Birhade A, Iyer K, Jadhav R, et al. (2017) Bioequivalence of Two Formulations of Salmeterol Xinafoate/Fluticasone Propionate HFA pMDI in Healthy Volunteers. J Bioequiv Availab 9: 536-546. doi: 10.4172/jbb.1000359

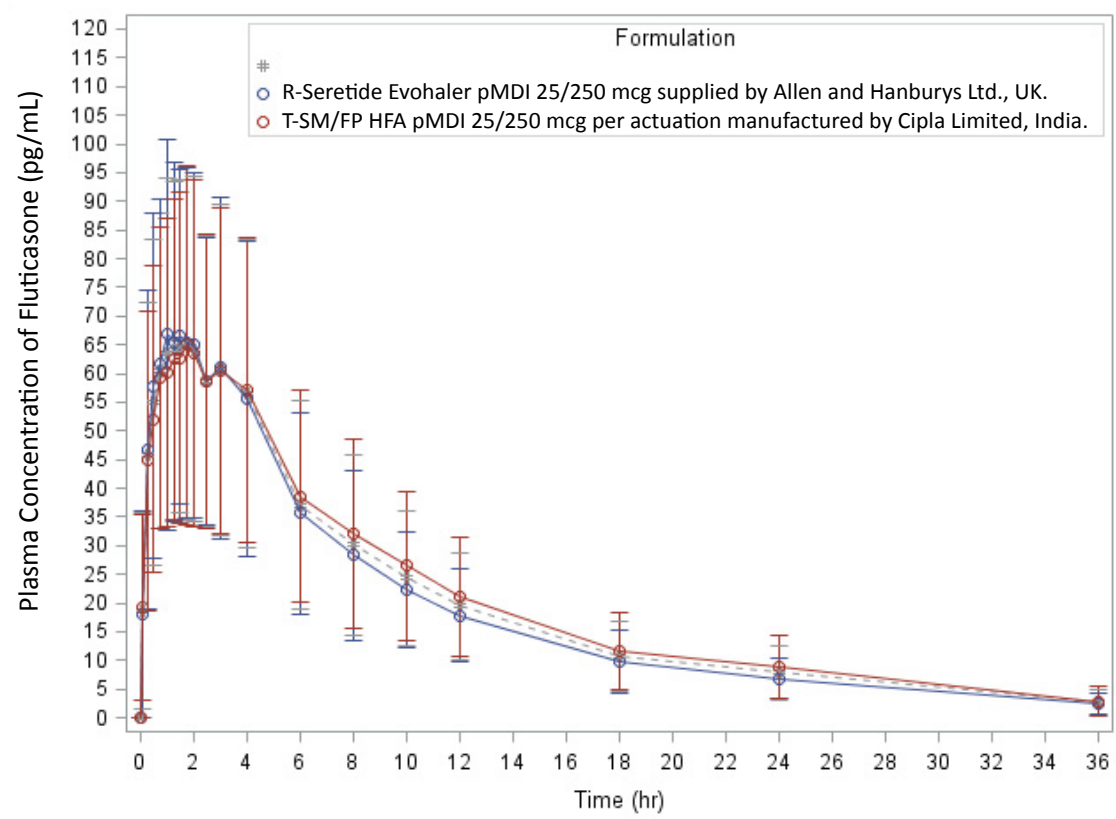

Figure 3: Mean graph (linear) for plasma concentration vs. time profile of Fluticasone propionate after inhalational dose of Salmeterol xinafoate/Fluticasone propionate (SM/FP) HFA pMDI 50/500 mcg in Study-2 (Salmeterol xinafoate/Fluticasone propionate (SM/FP) HFA pMDI $25 / 250$ mcg per actuation without charcoal).

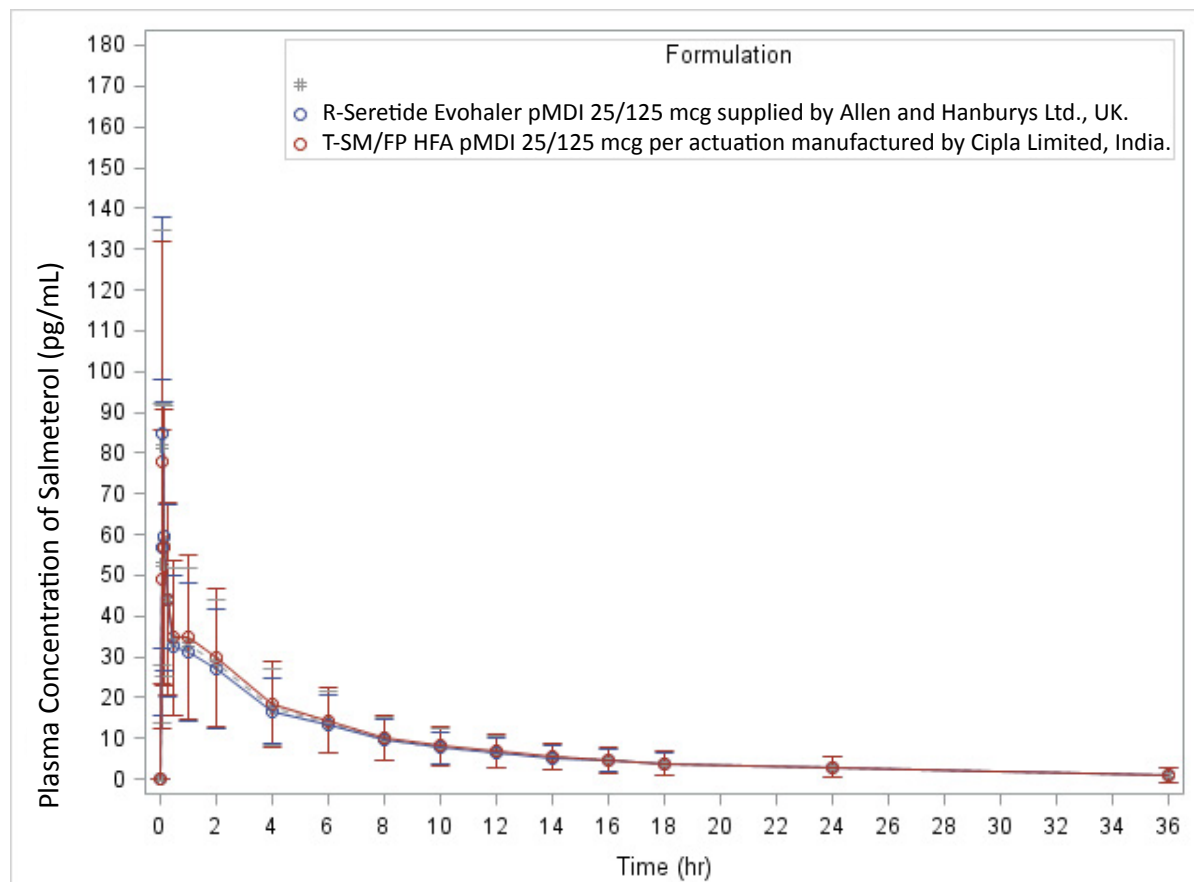

Figure 4: Mean graph (linear) for plasma concentration vs. time profile of Salmeterol xinafoate after inhalational dose of Salmeterol xinafoate/Fluticasone propionate (SM/FP) HFA pMDI 50/250 mcg in Study-3 (Salmeterol xinafoate/Fluticasone propionate (SM/FP) HFA pMDI 25/125 mcg per actuation with and without charcoal)

xinafoate with charcoal over the 36-hour pharmacokinetic study is presented in Figure 6 (with charcoal FPSM 25/125 mcg study-4). These figures suggest comparable mean plasma concentration-time curves for reference-test formulation corresponding to each study.
The mean ratios of $\mathrm{AUC}_{0+\mathrm{t}} / \mathrm{AUC}_{0-\infty}$ for all volunteers were found to be more than $80 \%$, indicating that blood samples collected adequately characterized the pharmacokinetic profile of the drug. The statistical results of the pharmacokinetic parameters of salmeterol xinafoate and 
Citation: Garg M, Naidu R, Birhade A, Iyer K, Jadhav R, et al. (2017) Bioequivalence of Two Formulations of Salmeterol Xinafoate/Fluticasone Propionate HFA pMDI in Healthy Volunteers. J Bioequiv Availab 9: 536-546. doi: 10.4172/jbb.1000359

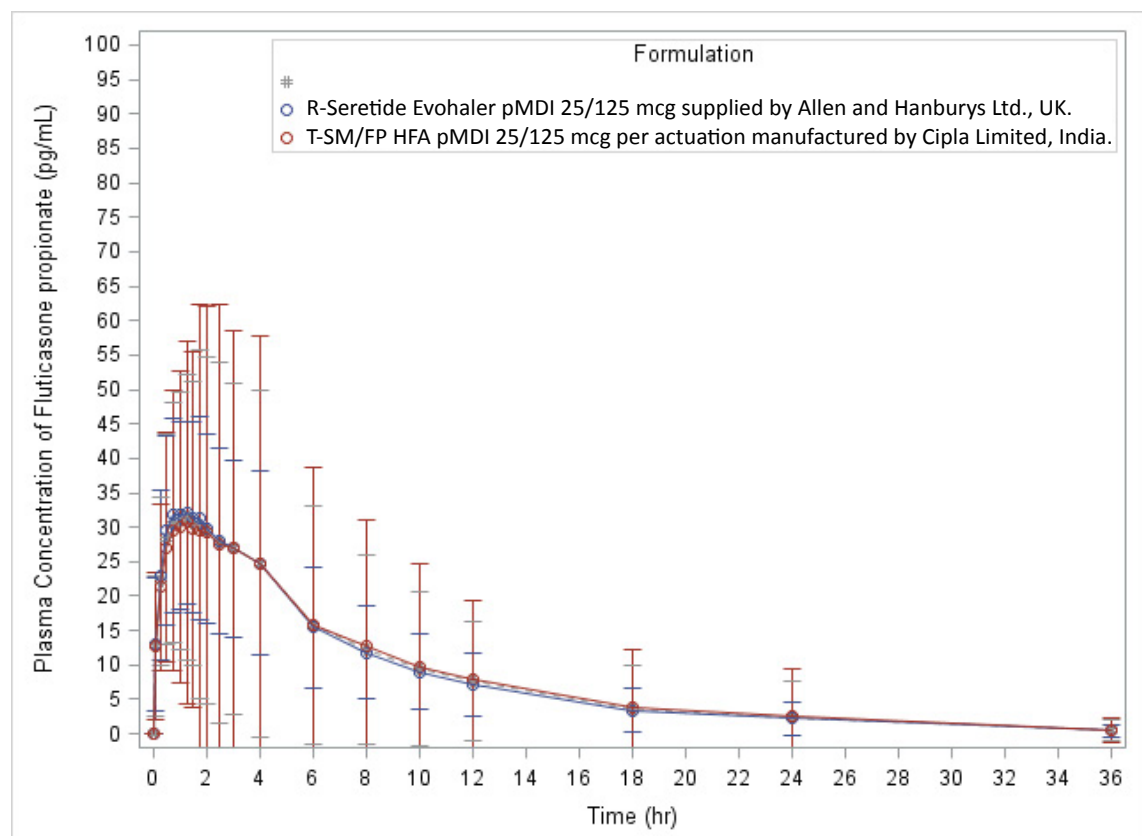

Figure 5: Mean graph (linear) for plasma concentration vs. time profile of Fluticasone propionate (without charcoal) after inhalational dose of Salmeterol xinafoate/Fluticasone propionate (SM/FP) HFA pMDI 50/250 mcg in Study-3 (Salmeterol xinafoate/Fluticasone propionate (SM/FP) HFA pMDI 25/125 mcg per actuation with and without charcoal).

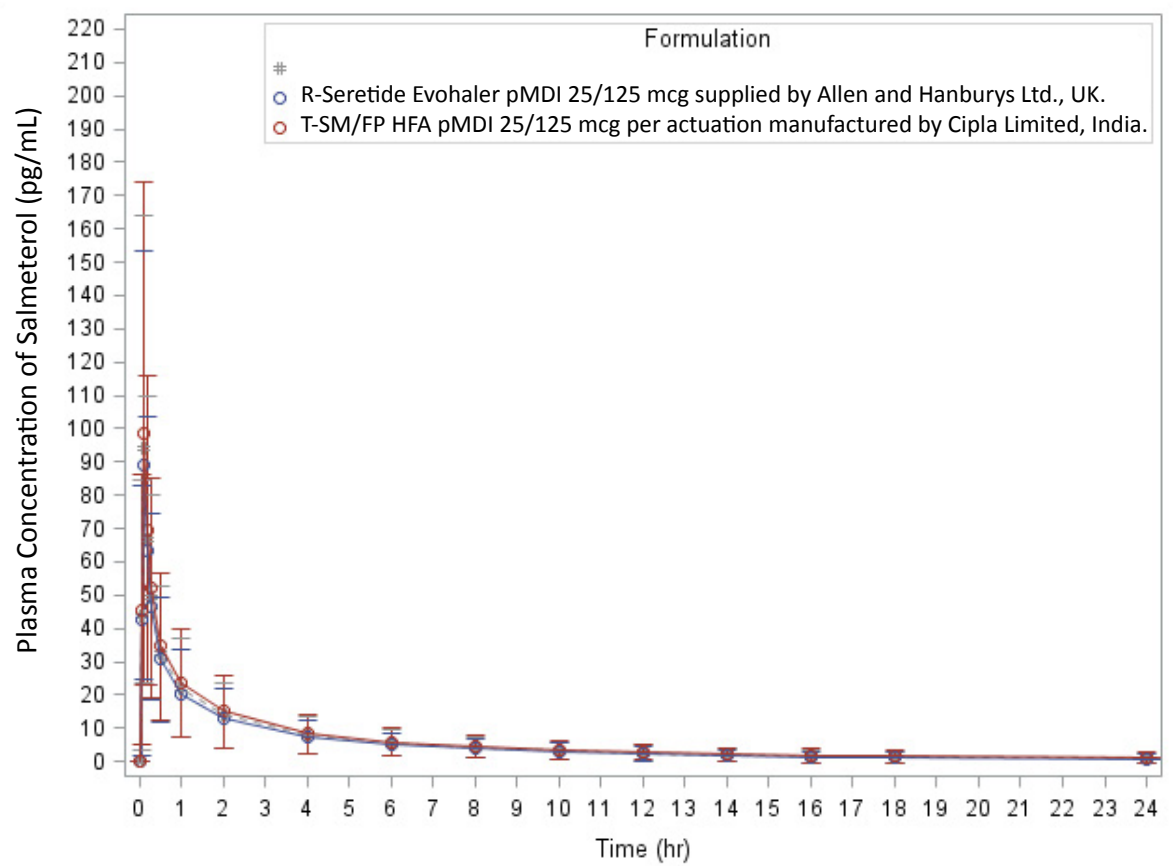

Figure 6: Mean graph (linear) for plasma concentration vs. time profile of Salmeterol xinafoate after inhalational dose of Salmeterol xinafoate/Fluticasone propionate (SM/FP) HFA pMDI 50/250 mcg in Study-4 (Salmeterol xinafoate/Fluticasone propionate (SM/FP) HFA pMDI 25/125 mcg per actuation with charcoal).

fluticasone propionate (for all studies) are presented in Tables 4 and 5 respectively. The geometric mean ratios, $90 \% \mathrm{CI}$, and intra subject coefficient of variation of test and reference for Ln transformed pharmacokinetic parameters $\mathrm{C}_{\max }$, and $\mathrm{AUC}_{0-\mathrm{t}}$ for salmeterol xinafoate and fluticasone propionate for all studies are presented in Tables 6 and 7 respectively. In the 2 pivotal PK studies with each strength, the absorption of fluticasone was equivalent to the reference product (Seretide Evohaler, UK) after administration. For salmeterol, in all the 4 pivotal PK studies (with and without charcoal blockade), almost all 8 of the 10 primary parameters fulfilled the pre-specified bioequivalence (BE) criteria (except for salmeterol in the third pivotal PK study due to very high variability in the charcoal arms). 
Citation: Garg M, Naidu R, Birhade A, Iyer K, Jadhav R, et al. (2017) Bioequivalence of Two Formulations of Salmeterol Xinafoate/Fluticasone Propionate HFA pMDI in Healthy Volunteers. J Bioequiv Availab 9: 536-546. doi: 10.4172/jbb.1000359

\begin{tabular}{|c|c|c|c|c|c|c|c|c|}
\hline \multirow{2}{*}{$\begin{array}{l}\text { Pharmacokinetic } \\
\text { Parameters }\end{array}$} & \multicolumn{2}{|c|}{ Salmeterol xinafoate (study-1) } & \multicolumn{2}{|c|}{ Salmeterol xinafoate (study-2) } & \multicolumn{2}{|c|}{ Salmeterol xinafoate (study-3) } & \multicolumn{2}{|c|}{ Salmeterol xinafoate (study-4) } \\
\hline & $\begin{array}{l}\text { Test (T) (Mean } \\
\pm \text { SD) }\end{array}$ & $\begin{array}{c}\text { Reference (R) } \\
(\text { Mean } \pm \text { SD) }\end{array}$ & $\begin{array}{c}\text { Test (T) (Mean } \\
\pm \text { SD) }\end{array}$ & $\begin{array}{c}\text { Reference (R) } \\
\text { (Mean } \pm \text { SD) }\end{array}$ & $\begin{array}{c}\text { Test (T) (Mean } \\
\pm \text { SD) }\end{array}$ & $\begin{array}{l}\text { Reference (R) } \\
\text { (Mean } \pm \text { SD) }\end{array}$ & $\begin{array}{c}\text { Test (T) (Mean } \\
\pm \text { SD) }\end{array}$ & $\begin{array}{c}\text { Reference (R) } \\
\text { (Mean } \pm \text { SD) }\end{array}$ \\
\hline $\mathbf{N}$ & 78 & 78 & 56 & 56 & 63 & 63 & 68 & 68 \\
\hline$C_{\max }(p g / m l)$ & $104.11 \pm 54.80$ & $114.67 \pm 74.86$ & $90.97 \pm 60.06$ & $96.19 \pm 57.08$ & $85.20 \pm 55.20$ & $89.55 \pm 53.91$ & $105.91 \pm 75.47$ & $94.26 \pm 63.49$ \\
\hline $\mathrm{AUC}_{0-0.50}$ (hr.pg/ml) & $30.28 \pm 17.04$ & $27.71 \pm 12.49$ & $25.69 \pm 14.17$ & $25.54 \pm 13.03$ & $24.46 \pm 13.29$ & $24.57 \pm 13.01$ & $27.55 \pm 16.63$ & $24.57 \pm 14.42$ \\
\hline $\mathrm{AUC}_{0 . \mathrm{t}}(\mathrm{hr} . \mathrm{pg} / \mathrm{ml})$ & $149.64 \pm 68.33$ & $163.85 \pm 80.82$ & $290.36 \pm 122.04$ & $263.73 \pm 129.68$ & $296.37 \pm 168.72$ & $275.17 \pm 147.62$ & $153.03 \pm 109.37$ & $128.21 \pm 89.51$ \\
\hline $\mathrm{AUC}_{0 . \infty}(\mathrm{hr} . \mathrm{pg} / \mathrm{ml})$ & $180.74 \pm 85.37$ & $195.46 \pm 94.40$ & $345.76 \pm 151.31$ & $310.86 \pm 147.21$ & $342.29 \pm 192.47$ & $325.89 \pm 177.27$ & $190.65 \pm 137.90$ & $162.21 \pm 113.73$ \\
\hline${ }^{*} \mathrm{~T}_{\max }(\mathrm{hr})$ & $0.08(0.05-0.50)$ & $0.08(0.05-0.50)$ & $0.08(0.05-2.00)$ & $0.08(0.05-2.00)$ & $0.08(0.08-2.00)$ & $0.08(0.05-2.00)$ & $0.08(0.08-0.52)$ & $0.08(0.07-0.50)$ \\
\hline$K_{e l}(1 / h r)$ & $0.115 \pm 0.049$ & $0.125 \pm 0.122$ & $0.085 \pm 0.041$ & $0.084 \pm 0.040$ & $0.078 \pm 0.032$ & $0.078 \pm 0.037$ & $0.195 \pm 0.503$ & $0.180 \pm 0.317$ \\
\hline $\mathrm{T}_{1 / 2}(\mathrm{hr})$ & $7.23 \pm 3.47$ & $7.03 \pm 3.13$ & $11.36 \pm 8.46$ & $10.82 \pm 6.43$ & $10.57 \pm 4.65$ & $11.34 \pm 5.60$ & $10.72 \pm 15.11$ & $9.85 \pm 10.40$ \\
\hline
\end{tabular}

Table 4: The statistical results of primary pharmacokinetic parameters of Salmeterol xinafoate for Study-1 (Salmeterol xinafoate/Fluticasone propionate HFA pMDI 25/250 mcg per actuation with charcoal); Study-2 (Salmeterol xinafoate/Fluticasone propionate HFA pMDI 25/250 mcg per actuation without charcoal); Study-3 (Salmetero xinafoate/Fluticasone propionate HFA pMDI 25/125 mcg per actuation with and without charcoal) and Study-4 (Salmeterol xinafoate/Fluticasone propionate HFA pMDI $25 / 125$ mcg per actuation with charcoal) are presented.

\begin{tabular}{|c|c|c|c|c|}
\hline \multirow{2}{*}{ Pharmacokinetic Parameters } & \multicolumn{2}{|c|}{ Fluticasone propionate (Study-2) } & \multicolumn{2}{|c|}{ Fluticasone propionate (Study-3) } \\
\hline & Test $(T)$ (Mean \pm SD) & Reference $(R)$ (Mean $\pm S D$ ) & Test $(T)($ Mean \pm SD) & Reference $(R)$ (Mean $\pm S D$ ) \\
\hline $\mathbf{N}$ & 55 & 55 & 63 & 63 \\
\hline $\mathrm{C}_{\max }(\mathrm{pg} / \mathrm{ml})$ & $74.09 \pm 32.27$ & $76.50 \pm 34.50$ & $39.75 \pm 37.15$ & $38.79 \pm 16.29$ \\
\hline $\mathrm{AUC}_{0 . \mathrm{t}}(\mathrm{hr} . \mathrm{pg} / \mathrm{ml})$ & $713.02 \pm 337.41$ & $652.39 \pm 301.32$ & $295.37 \pm 435.55$ & $275.32 \pm 159.19$ \\
\hline$A U C_{0 . \infty}(\mathrm{hr} . \mathrm{pg} / \mathrm{ml})$ & $771.55 \pm 359.04$ & $703.05 \pm 320.30$ & $330.04 \pm 454.81$ & $302.03 \pm 164.25$ \\
\hline $\mathrm{T}_{\text {max }}(\mathrm{hr})$ & $1.50(0.25-4.02)$ & $1.25(0.25-4.00)$ & $1.00(0.25-4.00)$ & $1.00(0.25-4.00)$ \\
\hline $\mathrm{K}_{\mathrm{el}}(1 / \mathrm{hr})$ & $0.083 \pm 0.023$ & $0.085 \pm 0.023$ & $0.120 \pm 0.057$ & $0.119 \pm 0.045$ \\
\hline $\mathrm{T}_{1 / 2}(\mathrm{hr})$ & $8.97 \pm 2.59$ & $8.82 \pm 2.65$ & $7.03 \pm 3.46$ & $6.60 \pm 2.31$ \\
\hline
\end{tabular}

Table 5: The statistical results of primary pharmacokinetic parameters of Fluticasone propionate for Study-2 (Salmeterol xinafoate/Fluticasone propionate HFA pMD $25 / 250$ mcg per actuation without charcoal), and Study-3 (Salmeterol xinafoate/Fluticasone propionate HFA pMDI 25/125 mcg per actuation with and without charcoal) are presented.

\begin{tabular}{|c|c|c|c|c|c|}
\hline \multirow{2}{*}{ Pharmacokinetic Parameters } & \multicolumn{2}{|c|}{ Geometric Mean } & \multirow{2}{*}{ *(\%)T/R } & \multirow{2}{*}{$90 \%$ Confidence Interval } & \multirow{2}{*}{ Intra subject CV\% } \\
\hline & Test & Ref & & & \\
\hline N (Study -1) & 78 & 78 & - & - & - \\
\hline$C_{\max }(p g / m L)$ & 93.73 & 90.82 & 103.21 & $94.10-113.20$ & $34.20^{* *}$ \\
\hline$A_{0-\mathrm{t}}(\mathrm{hr} . \mathrm{pg} / \mathrm{mL})$ & 138.76 & 130.80 & 106.08 & $96.44-116.69$ & $38.99^{*+*}$ \\
\hline N (Study-2) & 56 & 56 & - & - & \\
\hline$C_{\max }(p g / m L)$ & 75.24 & 82.25 & 91.47 & $83.44-100.29$ & 29.60 \\
\hline$A C_{0-t}(\mathrm{hr} . \mathrm{pg} / \mathrm{mL})$ & 265.59 & 237.57 & 111.79 & 104.08-120.08 & 22.82 \\
\hline N (Study -3) & 63 & 63 & - & - & \\
\hline$C_{\max }(p g / m L)$ & 72.03 & 74.26 & 96.80 & $88.33-106.08$ & 31.45 \\
\hline$A^{\prime} C_{0-t}(\mathrm{hr} . p g / m L)$ & 255.39 & 237.06 & 107.44 & $100.49-114.88$ & 22.73 \\
\hline N (Study -4) & 68 & 68 & - & - & - \\
\hline$C_{\max }(p g / m L)$ & 84.19 & 77.99 & 107.95 & $100.70-115.72$ & $28.09^{* *}$ \\
\hline $\mathrm{AUC}_{0-\mathrm{t}}(\mathrm{hr} . \mathrm{pg} / \mathrm{mL})$ & 109.39 & 96.38 & 113.50 & $104.99-122.70$ & $32.78^{* *}$ \\
\hline
\end{tabular}

Table 6: The Geometric mean ratios, $90 \% \mathrm{Cls}$, power and intra subject coefficient of variation of test and reference for $\mathrm{Ln}$ transformed pharmacokinetic parameters $\mathrm{C}_{\max }$ and AUC0-t for Salmeterol xinafoate of Study-1 (Salmeterol xinafoate/Fluticasone propionate HFA pMDI 25/250 mcg per actuation with charcoal); Study-2 (Salmetero xinafoate/Fluticasone propionate HFA pMDI 25/250 mcg per actuation without charcoal); Salmeterol xinafoate of Study-3 (Salmeterol xinafoate/Fluticasone propionate HFA pMDI 25/125 mcg per actuation without charcoal) and Study-4 (Salmeterol xinafoate/Fluticasone propionate HFA pMDI 25/125 mcg per actuation with charcoal) are presented.

In the pivotal study-3, for salmeterol with charcoal administration, both $\mathrm{C}_{\max }$ and $\mathrm{AUC}_{0-\mathrm{t}}$ for salmeterol with charcoal were marginally outside the accepted bioequivalence range of $80-125 \%$ (90\% CI for $\mathrm{C}_{\max }$ was 77.23 - 94.94; 90\% CI for $\mathrm{AUC}_{0-\mathrm{t}}$ was 71.25 - 96.11). However, it is important to note that the \% CV was high ( $>36 \%$ for $\mathrm{C}_{\max }$ and $>55 \%$ for $\mathrm{AUC}_{0-\mathrm{t}}$ ) for both the test and reference products in the presence of oral charcoal blockade. As a result, there was inadequate power for the salmeterol PK bioequivalence assessments in the presence of oral 


\begin{tabular}{|c|c|c|c|c|c|}
\hline \multirow{2}{*}{ Pharmacokinetic Parameters } & \multicolumn{2}{|c|}{ Geometric Mean } & \multirow{2}{*}{${ }^{*}(\%) T / R$} & \multirow{2}{*}{$\mathbf{9 0} \%$ Confidence Interval } & \multirow{2}{*}{ Intra subject CV\% } \\
\hline & Test & Ref & & & \\
\hline N (Study -2) & 55 & 55 & - & - & \\
\hline$C_{\max }(p g / m L)$ & 67.83 & 69.34 & 97.83 & $91.08-105.07$ & 22.60 \\
\hline AUC $_{0-\mathrm{t}}(\mathrm{hr} . \mathrm{pg} / \mathrm{mL})$ & 631.67 & 587.89 & 107.45 & $99.86-115.61$ & 21.84 \\
\hline N (Study -3) & 63 & 63 & - & - & \\
\hline$C_{\max }(p g / m L)$ & 33.60 & 35.07 & 95.61 & $87.04-105.03$ & 32.31 \\
\hline$A U C_{0-t}(\mathrm{hr} . \mathrm{pg} / \mathrm{mL})$ & 217.69 & 231.10 & 93.97 & $85.38-103.42$ & 32.99 \\
\hline
\end{tabular}

*\%) T/R is ratio of Test Geometric Mean / Ref Geometric Mean

"intra-subject variability for reference product

Table 7: The Geometric mean ratios, $90 \% \mathrm{Cls}$, power and intra subject coefficient of variation of test and reference for Ln transformed pharmacokinetic parameters $\mathrm{C}_{\max }$, and $\mathrm{AUC}_{0-\mathrm{t}}$ for Fluticasone propionate of Study-2 (Salmeterol xinafoate/Fluticasone propionate HFA pMDI 25/250 mcg per actuation without charcoal) and Study-3 (Salmeterol xinafoate/Fluticasone propionate HFA pMDI 25/125 mcg per actuation with and without charcoal) are presented.

\begin{tabular}{|c|c|c|c|c|}
\hline \multirow{2}{*}{ Study No (Number of subjects) } & \multirow{2}{*}{ Strength } & \multirow{2}{*}{$\begin{array}{l}\text { Number of volunteers reporting AEs } \\
\text { (Number of AEs) }\end{array}$} & \multicolumn{2}{|c|}{ Number of Adverse Events } \\
\hline & & & Test product $(\mathrm{T})$ & Reference product (R) \\
\hline Study $1(\mathrm{~N}=42)$ & $25 / 250$ & $11(19)$ & 12 & 7 \\
\hline Study $2(N=74)$ & $25 / 250$ & $11(14)$ & 8 & 6 \\
\hline Study $3(\mathrm{~N}=80)$ & $25 / 125$ & $22(28)$ & 13 & 15 \\
\hline Study $4(\mathrm{~N}=72)$ & $25 / 125$ & $15(16)$ & 9 & 7 \\
\hline Total & & $59(77)$ & 42 & 35 \\
\hline
\end{tabular}

Table 8: Incidence of adverse events pooled from all the 4 studies.

charcoal blockade, particularly for $\mathrm{AUC}_{0-\mathrm{t}}$. Hence, definitive conclusions regarding salmeterol PK bioequivalence between the test and reference product in the presence of oral charcoal blockade could not be made on the basis of this study. Hence, assessment of bioequivalence for salmeterol with charcoal blockade was done in the fourth pivotal PK study with a much larger sample size.

The secondary parameters $\mathrm{T}_{\max }$ and $\mathrm{T}_{1 / 2}$ were comparable between the test and the reference products in all studies. The median fluticasone $\mathrm{t}_{\max }$ varied from 1.00 to $1.50 \mathrm{~h}$ and median salmeterol $\mathrm{T}_{\max }$ was $0.08 \mathrm{~h}$ in different studies irrespective of the product. Mean $\mathrm{T}_{1 / 2}$ for fluticasone varied from 7.03 to $8.97 \mathrm{~h}$ and mean $\mathrm{T}_{1 / 2}$ for salmeterol from 7.03 to $11.36 \mathrm{~h}$ irrespective of the product. The obtained AUC $\infty$ values were in line with the corresponding $\mathrm{AUC}_{0-\mathrm{t}}$ values.

There were no safety issues in any of the studies and no serious AEs were reported. AE profiles were similar after both inhalers (Table 8). Most of the adverse events were mild to moderate intensity.

No deaths/ serious adverse event occurred during conduct of all the four studies. No clinically relevant changes were observed during vital signs examination, ECGs, and post-study clinical laboratory data. All volunteers were medically fit in post-study safety assessment.

\section{Discussion}

All 4 PK studies were conducted to compare the pulmonary deposition and total systemic exposure of the 2 strengths of fluticasone/ salmeterol MDI (Cipla Ltd) with the reference product. All studies were single dose, randomized crossover studies.

In accordance with the OIP guidance, PK studies in healthy volunteers were performed which together with the required in vitro investigations formed the basis of test product fluticasone/salmeterol HFA MDI marketing authorizations in Europe. The findings of studies in healthy volunteers can be bridged to patients as the MDI device do not have flow rate dependency characteristics.

Generally, there is good agreement between PK and in vitro data which aids in product development and helps ensure that the relative clinical efficacy and safety of the given drug formulation will be comparable to that of the reference product $[16,17]$.

PK studies can differentiate between systemic absorption (surrogate of safety) and lung absorption (surrogate of efficacy) using validated methodologies such charcoal blockade. For a PK study with charcoal blockade, or for a product with very low oral bioavailability, AUC is considered to be a direct reflection of the dose that reaches the lungs and subsequently passes from the lung epithelium into the systemic circulation. This is reflected in PK profiles as evident from studies with large versus small particle formulations of an inhaled drug [17]. Therefore a PK study can effectively evaluate relative lung distribution for an OIP through the standard AUC and $\mathrm{C}_{\max }$ parameters.

The established relationship between dose and lung/systemic exposure is generally dose proportional for both LABAs and ICSs. By contrast, the clinical efficacy dose response for both ICSs and LABAs are very flat and successive doses which result in marked increases in AUC and $\mathrm{C}_{\max }$ are not generally associated with any appreciable differences in efficacy. Therefore efficacy measures are very insensitive for detecting difference between corresponding doses of a test and reference product.

It has been shown that the same doses of a test and reference product which have comparable systemic exposure profiles also have comparable efficacy profiles [18]. However even when significant difference in the PK profiles are present when the same doses of a test and reference product are administered, no appreciable clinical differences are observed $[19,20]$. Hence, PK studies, unlike clinical efficacy studies are more sensitive to identify differences between formulations and assess equivalence.

In all the PK studies, the systemic exposure and pulmonary deposition of fluticasone/salmeterol MDI (Cipla Ltd, India) was equivalent to the reference product (Allen and Hanburys, UK).

\section{Conclusions}

The $90 \% \mathrm{CI}(\mathrm{T} / \mathrm{R})$ for salmeterol xinafoate and fluticasone propionate 
Citation: Garg M, Naidu R, Birhade A, lyer K, Jadhav R, et al. (2017) Bioequivalence of Two Formulations of Salmeterol Xinafoate/Fluticasone Propionate HFA pMDI in Healthy Volunteers. J Bioequiv Availab 9: 536-546. doi: 10.4172/jbb.1000359

for both $\mathrm{C}_{\text {max }}$ and $\mathrm{AUC}_{0-\mathrm{t}}$ was within $80.00-125.00 \%$ with and without charcoal blockade, suggesting that both the formulations of salmeterol xinafoate/fluticasone propionate HFA pMDI are bioequivalent in their rate and extent of absorption for both the strengths. Since the test product has been shown to have equivalent pulmonary absorption and systemic exposure as that of the reference product, it is expected to have equivalent efficacy and safety as well.

\section{Acknowledgement}

These bioequivalence studies were conducted at Sitec Labs. Pvt. Ltd., Mumbai, India. Dr Muneesh Garg was the Principal Investigator for all the studies, wrote the manuscript, and reviewed and approved the final draft. Dr Raghu Naidu was responsible for the bio-analysis. This publication was supported by Sitec Labs., India; and Cipla Ltd., India was the sponsor of these studies.

The authors have indicated that they have no other conflicts of interest regarding the content of the article. The authors are thankful to the volunteers who participated in this study.

\section{References}

1. Bateman E, Hurd SS, Barnes PJ, Bousquet J, Drazen JM, et al. (2008) Global strategy for asthma management and prevention: GINA executive summary. Eur Respir J 31: 143-178.

2. Haahtela T, Jarvinen M, Kava T, Kiviranta K, Koskinen S, et al. (1991) Comparison of a $\beta_{2}$-agonist, terbutaline, with an inhaled corticosteroid, budesonide, in newly detected asthma. N Engl J Med. 325: 388-392.

3. Barnes PJ (2002) Scientific rationale for inhaled combination therapy with longacting $\beta_{2}$-agonists and corticosteroids. Eur Respir J 19: 182-191.

4. CHMP (2009) Guideline on the requirements for clinical documentation for orally inhaled products (OIP) including the requirements for demonstration of therapeutic equivalence between two inhaled products for use in the treatment of Asthma and Chronic Obstructive Pulmonary Disease (COPD), UK.

5. Irish Medicines Board (2010) Summary of Product Characteristics: Carbomix (activated charcoal) $50 \mathrm{gm}$, Beacon Pharmaceuticals Ltd, UK. Electronic Medicines Compendium

6. World Medical Association Declaration of Helsinki (2008) Ethical principles for the medical research involving human volunteers adopted by the: 59th General Assembly, Seoul, Korea.

7. ICMR Guidelines (2006) Ethical Guidelines for Biomedical Research on Human Participants. Indian Council of Medical Research, New Delhi, 1-111.

8. Schedule $Y$ (2014) Requirements and guidelines for permission to import and/ or manufacture of new drugs for sale or to undertake clinical trials. Central Drugs Standard Control Organization website. New Delhi, India.
9. $\mathrm{ICH}$ harmonised Tripartite Guideline - Guideline for Good Clinical Practice E6 (R1) (1996) International Conference on Harmonization of Technical Requirements for Registration of Pharmaceuticals for Human Use. J Postgrad Med 47: 45-50.

10. Bennett JA, Harrison TW, Tattersfield AE (1999) The contribution of the swallowed fraction of an inhaled dose of salmeterol to it systemic effects. Eur Respir J 13: 445-448.

11. Kunka R, Andrews S, Pimazzoni M, Callejas S, Ziviani L, et al. (2000) Dose proportionality of fluticasone propionate from hydrofluroalkane pressurised metered dose inhalers (pMDIs) and comparability with chloroflurocarbon pMDI. Respir Med 94: S10-16.

12. Blake K, Mehta R, Spencer T, Kunka RL, Hendeles L (2012) Bioavailability of inhaled fluticasone propionate via chambers/masks in young children. Eur Respir J 39: 97-103.

13. Dempsey OJ, Coutie WJR, Wilson AM, Williams P, Lipworth BJ (1999) Evaluation of the buccal component of systemic absorption with inhaled fluticasone propionate. Thorax 54: 614-617.

14. Committee for medicinal products for human use (CHMP) (2011) Guideline on Bio-analytical method validation. European medicines agency, London.

15. Food and drug administration (2013) Guidance for industry Bio-analytica method validation. Center for drug evaluation and research.

16. Woodcock A, Acerbi D, Poli G (2002) Modulite@ technology: pharmacodynamic and pharmacokinetic implications. Respiratory Medicine 96: S9-S15.

17. Clearie KL, Williamson PA, Meldrum K, Gillen M, Carlsson LG, et al. (2011) Pharmacokinetic and pharmacodynamic comparison of hydrofluoroalkane and chlorofluorocarbon formulations of budesonide. $\mathrm{Br} \mathrm{J}$ Clin Pharmacol 71 : 504-513.

18. Houghton CM, Langley SJ, Singh SD, Holden J, Monici Preti AP, et al. (2004) Comparison of bronchoprotective and bronchodilator effects of a single dose of formoterol delivered by hydrofluoroalkane and chlorofluorocarbon aerosols and dry powder in a double blind, placebocontrolled, crossover study. $\mathrm{Br} \mathrm{J}$ Clin Pharmacol 58: 359-366.

19. Daley-Yates PT, Parkins DA, Thomas MJ, Gillett B, House KW, et al. (2009) Pharmacokinetic, pharmacodynamic, efficacy, and safety data from two randomized, double-blind studies in patients with asthma and an in vitro study comparing two dry-powder inhalers delivering a combination of salmeterol 50 microg and fluticasone propionate 250 microg: implications for establishing bioequivalence of inhaled products. Clin Ther 31: 370-385.

20. Pearlman DS, Noonan MJ, Tashkin DP, Goldstein MF, Hamedani AG, et al (1997) Comparative efficacy and safety of twice daily fluticasone propionate powder versus placebo in the treatment of moderate asthma. Ann Allergy Asthma Immunol 78: 356-362. 